\title{
Biological impact of superparamagnetic iron oxide nanoparticles for magnetic particle imaging of head and neck cancer cells
}

This article was published in the following Dove Press journal:

International Journal of Nanomedicine

29 October 2014

Number of times this article has been viewed

\author{
Antje Lindemann' \\ Kerstin Lüdtke-Buzug ${ }^{2}$ \\ Bianca M Fräderich' \\ Ksenija Gräfe ${ }^{2}$ \\ Ralph Pries' \\ Barbara Wollenberg' \\ 'Department of Otorhinolaryngology, \\ University Hospital of Schleswig- \\ Holstein, Luebeck, Germany; ${ }^{2}$ Institute \\ of Medical Engineering, University \\ of Luebeck, Luebeck, Germany
}

Background: As a tomographic imaging technology, magnetic particle imaging (MPI) allows high spatial resolution and sensitivity, and the possibility to create real-time images by determining the spatial distribution of magnetic particles. To ensure a prospective biosafe application of UL-D (University of Luebeck-Dextran coated superparamagnetic nanoparticles), we evaluated the biocompatibility of superparamagnetic iron oxide nanoparticles (SPIONs), their impact on biological properties, and their cellular uptake using head and neck squamous cancer cells (HNSCCs).

Methods: SPIONs that met specific MPI requirements were synthesized as tracers. Labeling and uptake efficiency were analyzed by hematoxylin and eosin staining and magnetic particle spectrometry. Flow cytometry, 3-(4,5-Dimethylthiazol-2-yl)-2,5-diphenyl tetrazolium bromide (MTT) assays, and real-time cell analyzer assays were used to investigate apoptosis, proliferation, and the cytokine response of SPION-labeled cells. The production of reactive oxygen species (ROS) was determined using a fluorescent dye. Experimental results were compared to the contrast agent Resovist ${ }^{\circledR}$, a standard agent used in MPI.

Results: UL-D nanoparticles and Resovist particles were taken up in vitro by HNSCCs via unspecific phagocytosis followed by cytosolic accumulation. To evaluate toxicity, flow cytometry analysis was performed; results showed that dose- and time-dependent administration of Resovist induced apoptosis whereas cell viability of UL-D-labeled cells was not altered. We observed decreased cell proliferation in response to increased SPION concentrations. An intracellular production of ROS could not be detected, suggesting that the particles did not cause oxidative stress. Tumor necrosis factor alpha (TNF- $\alpha$ ) and interleukins IL-6, IL- 8 , and IL-1 $\beta$ were measured to distinguish inflammatory responses. Only the primary tumor cell line labeled with $>0.5 \mathrm{mM}$ Resovist showed a significant increase in IL-1 $\beta$ secretion.

Conclusion: Our data suggest that UL-D SPIONs are a promising tracer material for use in innovative tumor cell analysis in MPI.

Keywords: cell labeling, HNSCCs, biomedical imaging, iron oxide nanoparticles, cytotoxicity

\section{Introduction}

The use of superparamagnetic iron oxide nanoparticles (SPIONs) for numerous biomedical applications is based on their unique properties. The nanoscale structure and features of superparamagnetism offer a variety of possibilities for treatment and diagnostic medical applications. ${ }^{1}$ SPIONs are used as tracer material in magnetic particle imaging (MPI). MPI was introduced in 2005 as a novel tomographic imaging modality. ${ }^{2}$ The nonlinear magnetization of SPIONs is the key element for their use as a tracer in MPI. The particles are stimulated by a sinusoidal signal called the drive field that
Correspondence: Barbara Wollenberg Department of Otorhinolaryngology, University Hospital of Schleswig-Holstein Campus Luebeck, Ratzeburger Allee 160, 23538 Luebeck, Germany

Tel +49 45I 500224 I

$\mathrm{Fax}+494515002249$

Email barbara.wollenberg@uk-sh.de 
induces a voltage in the receive coil. For spatial encoding, a field-free point (FFP) in the field of view is necessary because only the SPIONs in the FFP respond to the excitation signal. The signal contains an excitation frequency $(\sim 25 \mathrm{kHz})$ and its harmonics, which are caused by the nonlinearity of the SPIONs' magnetization. The advantages of MPI over current imaging techniques are high spatial resolution and sensitivity, and the potential for high quality real-time imaging. ${ }^{3}$ Early experimental studies showed a resolution of $<1 \mathrm{~mm}$ and a fast dynamic process with an acquisition time of $<0.1$ second. ${ }^{4,5}$ Furthermore, a good signal-to-noise ratio and excellent contrast confirm a promising imaging modality. ${ }^{6}$

The nanoparticle design is an important factor because the imaging principle is based on the superparamagnetic nature of SPIONs. Image quality of the MPI approach is determined by the spatial biodistribution of the particles. Moreover, particle size distribution affects the magnetization response of MPI. ${ }^{7}$ The larger the particle core, the steeper the nonlinear magnetization curve and the better the sensitivity. Therefore, spatial resolution and signal-to-noise ratio of MPI depend on the SPIONs' core diameter and homogeneity.

Resovist $^{\circledR}$ (Bayer Schering Pharma AG, Leverkusen, Germany), which consists of a carboxydextran-coated iron oxide, is a well-established iron oxide-based magnetic resonance imaging (MRI) contrast agent. It was used in the first successful phantom MPI experiments and in in vivo studies due to its large magnetic moment and short relaxation time, which are suitable for MPI., ${ }^{2,4}$ Resovist has an optimal nanoparticle size and contributes to significant MPI signals. It was initially adapted for use in MRI despite its shortcomings. The main difference is that in MPI, the signal of the SPIONs can be directly measured, whereas in MRI, SPIONs are measured by local distortion of the magnetic field. As a result, SPION contrast agents improve visualization of anatomical structures. In MPI, the tracer material is solely responsible for the signal; it does not provide any information about the anatomy of the object. For efficient utilization, iron oxide particles should ideally be of uniform size. Unfortunately, the efficiency of Resovist is unsatisfactory since only a small percentage of the iron accounts for MPI performance. Moreover, Resovist exhibits partially clustered iron oxide cores. ${ }^{8}$ It was withdrawn from the market in 2008 and there are no adequate substitute tracers commercially available for MPI at the present time. As a result, the current study designed and synthesized superparamagnetic iron oxide nanoparticles as MPI tracers.

Various approaches for synthesizing SPIONs were standardized and we chose a classical co-precipitation approach to produce particles with a reproducible quality. The challenge of SPION synthesis is to produce tracers with an optimal magnetic particle spectroscopy (MPS) performance. By means of MPS, it is possible to determine the SPION quality for MPI. ${ }^{9}$ The nanoparticles, namely UL-D, consist of an iron oxide core. For clinical and preclinical use, UL-D should combine the characteristics of biocompatibility, biodegradability, and biosafety with the SPIONs' surface characteristics, since these are key factors. ${ }^{10}$ Dextran (mw $70 \mathrm{kDa}$ ) was used to stabilize the particles in solution and prevent agglomeration. The coating material is important for particle uptake by cells. It has been shown that nanoparticle uptake can result in altered cell morphology, viability, and metabolism. In addition, SPION uptake can cause intracellular stress. Changes in mitochondrial function, permeability of the plasma membrane, inflammation, generation of reactive oxygen species (ROS), and directly associated protein and lipid peroxidation and chromosome condensation can lead to cell damage, mutations, and cancer. ${ }^{11-15}$ Therefore, it is necessary to study and ensure the biocompatibility and biosafety of SPIONs since they can be used in different applications for medical imaging and biomedical areas depending on their particle size.

Diagnostic and therapeutic imaging possibilities, including cardiovascular and oncological applications, are promising. ${ }^{16,17}$ The current study focused on the field of oncology. Cancer, including head and neck cancer, is one of the leading causes of death in the world. Head and neck squamous cell carcinoma (HNSCC) is the sixth most common cancer worldwide, with a mortality rate of $>50 \% .{ }^{18} \mathrm{By}$ improving therapeutic and diagnostic approaches, the survival rate of cancer patients could be improved. Tumor and metastatic measurements by MPI could improve tumor staging, optimize therapeutic plans, and provide early tumor detection. For fundamental research, labeled cells could be used for in vivo migration studies. ${ }^{19}$ This is why we analyzed cellular UL-D nanoparticle uptake and UL-D influence on various biological properties on HNSCCs compared to the contrast agent Resovist.

\section{Materials and methods \\ Particle preparation}

UL-D nanoparticles were synthesized by classical co-precipitation of iron oxide in an alkaline solution in the presence of dextran, a high molecular weight polymer of d-glucose. ${ }^{20,21}$ Six mmol iron (II) chloride tetrahydrate $\left(\mathrm{FeCl}_{2} \cdot 4 \mathrm{H}_{2} \mathrm{O}\right)$ and $27.8 \mathrm{mmol}$ iron (III) chloride hexahydrate $\left(\mathrm{FeCl}_{3} \cdot 6 \mathrm{H}_{2} \mathrm{O}\right)$ (VWR International GmbH, Darmstadt, Germany)

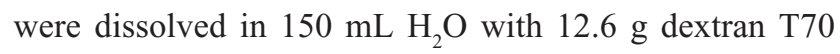


(MW 70,000; Carl Roth GmbH \& Co., KG, Karlsruhe, Germany). Iron hydroxide precipitated after dropwise addition of $150 \mathrm{~mL} 7.5 \%$ base ammonia $\left(\mathrm{NH}_{3}\right)$ at room temperature. After heating the solution for 30 minutes to 60 minutes at $70^{\circ} \mathrm{C}$, the iron hydroxide was reduced to iron oxide and $\mathrm{Fe}_{3} \mathrm{O}_{4}$ and dextran enclosed the particles. After synthesis, the particles were centrifuged for size separation and dialyzed against $\mathrm{H}_{2} \mathrm{O}$. Several steps of separation and purification were performed to concentrate the nanoparticles.

\section{Particle characterization}

To assess shape and particle size distribution, the nanoparticles were characterized by high-resolution transmission electron microscopy (HRTEM) (Philips Deutschland GmbH, Hamburg, Germany). The coating was removed and only the core was measured. Iron concentration of the nanoparticles was determined by photometry of the iron complex using Prussian blue. 22,23 The hydrodynamic diameter $\left(d_{h}\right)$ was used to test stability and was determined by dynamic light scattering based on photon cross-correlation spectroscopy (PCCS) (NANOPHOX, Sympatec, Clausthal-Zellerfeld, Germany). ${ }^{24,25}$ To estimate the core diameter of the SPIONs, atomic force microscopy (AFM) (DME Nanotechnologie $\mathrm{GmbH}$, Hannover, Germany) was used. ${ }^{26}$ For measurement, the particles were dissolved in $\mathrm{H}_{2} \mathrm{O}$ without addition of stabilizers. Stability experiments were conducted using Dulbecco's Modified Eagle's Medium (DMEM) or $\mathrm{H}_{2} \mathrm{O}$ as solution. Twenty-five $\mu \mathrm{L}$ and $100 \mu \mathrm{L}$ UL-D were diluted in a $3 \mathrm{~mL}$ solution and the hydrodynamic diameter of UL-D was measured by PCCS. Resovist has a crystal structure of $\mathrm{Fe}_{3} \mathrm{O}_{4}$ (magnetite) coated with carboxydextran and is available in a concentration of $0.5 \mathrm{mmol} / \mathrm{mL}(28 \mathrm{mg} / \mathrm{mL}) \mathrm{Fe}$. Core diameter is between $3 \mathrm{~nm}$ and $5 \mathrm{~nm}$ (mean, $4.2 \mathrm{~nm}$ ). ${ }^{27}$

\section{Magnetic particle spectroscopy}

For all MPS measurements, an excitation field strength of $\mathrm{H}=20 \mathrm{mT}$ and excitation frequency of $25 \mathrm{kHz}$ were used. Sample volume was $10 \mu \mathrm{L} .{ }^{9}$

\section{Cell culture}

Two HNSCC cell lines were established from primary cell carcinoma of the tonsilla (UT-SCC-60A) and the corresponding metastasis (UT-SCC-60B) and were used for cell labeling. ${ }^{28}$ They were cultured in DMEM supplemented with $10 \%$ fetal bovine serum (FBS) at $37^{\circ} \mathrm{C}$ and $5 \% \mathrm{CO}_{2}$ in a humidified atmosphere. Cells were subcultured using Accutase $^{\circledR}$ (all from GE Healthcare Life Sciences, Muenchen, Germany) upon reaching $80 \%$ to $90 \%$ confluence.
Particle concentration and incubation time

Cells were incubated with either UL-D or Resovist in concentrations of $0.2 \mathrm{mM}, 0.5 \mathrm{mM}, 0.9 \mathrm{mM}$, and $1.8 \mathrm{mM} \mathrm{Fe}$, respectively, for various durations. Unlabeled cells of each cell line were used in parallel as controls. After incubation, media were removed and cells were washed three times with phosphate buffered saline (PBS) buffer to wash out non-internalized particles.

\section{Mitochondrial activity}

Growth behavior of the cells was determined by colorimetric 3-(4,5-Dimethylthiazol-2-yl)-2,5-diphenyl tetrazolium bromide (MTT) assay. Ten $\mu \mathrm{L}$ of MTT $(5 \mathrm{mg} / \mathrm{mL}$; SigmaAldrich) was added for 1 hour at $37^{\circ} \mathrm{C}$ and discontinued with $100 \mu \mathrm{L}$ of MTT stop solution (Sigma-Aldrich). After shaking for 24 hours, absorbance was measured at $570 \mathrm{~nm}$ using a Benchmark Plus microplate reader (BioRad, Hercules, CA, USA).

\section{Nanoparticle cytotoxicity}

For annexin V-APC-PI staining, cells were stained with $2 \mu \mathrm{L}$ Annexin V-APC and $2 \mu \mathrm{L}$ propidium iodide (PI) in annexin $\mathrm{V}$ binding buffer (both Becton, Dickinson [BD] and Company, Franklin Lakes, NJ, USA) for 15 minutes. After two washes, the pellet was resuspended in $0.5 \mathrm{~mL}$ PBS and immediately measured with a BD FACSCanto ${ }^{\mathrm{TM}}$ flow cytometer (BD). Annexin V-APC was analyzed at an excitation level of $488 \mathrm{~nm}$ and emission level of $530 \mathrm{~nm}$. PI fluorescence was performed at excitation and emission levels of $488 \mathrm{~nm}$ and $585 \mathrm{~nm}$.

\section{Proliferation assay}

Using an xCELLigence DP analysis system (Roche Diagnostics, Rotkreuz, Switzerland), real-time measurement of cell proliferation was performed. Real-time cell analyzer assay was performed as per instructions.

\section{Nanoparticle uptake}

Cells were incubated with rhodamine-labeled UL-D for flow cytometry analysis. Rhodamine fluorescence was performed at excitation and emission levels of $488 \mathrm{~nm}$ and $585 \mathrm{~nm}$ on a FACSCanto cyclometer (BD). For immunohistochemistry analysis, the labeled streptavidin biotin method was used as follows. Cells were fixed with $70 \%$ ice-cold methanol for 15 minutes. After cell permeabilization with $0.3 \%$ Triton X-100/Tris-buffered saline (TBS) buffer for 5 minutes, cells were washed and $3 \% \mathrm{H}_{2} \mathrm{O}_{2}$ was added for 15 minutes. Anti-dextran antibody (1:150, clone DX-1; STEMCELL 
Technologies Inc., Vancouver, BC, Canada) was incubated for 2 hours at $37^{\circ} \mathrm{C}$. Next, slides were rinsed in TBS and a PolyLink secondary antibody was added (20 minutes at room temperature). Cells were then washed and incubated in a horseradish peroxidase detection system (both from DCS Diagnostic Systems, Hamburg, Germany) for 20 minutes. Slides were then rinsed thoroughly and AEC (3-Amino-9ethylcarbazole) substrate working solution (Vector Laboratories, Burlingame, CA, USA) was added. The reaction was stopped with TBS. Nuclei counterstaining was conducted with hematoxylin and eosin (H\&E). An Axiovert 200M optical microscope (Carl Zeiss Meditec, Oberkochen, Germany) was used to image cell morphology and nanoparticle uptake.

\section{Cytokine analysis}

Bead-based immunoassays were used to determine secretion changes of interleukins- 6 (IL-6), -8 (IL-8), and - $1 \beta$ (IL-1 $\beta$ ) and tumor necrosis factor alpha (TNF- $\alpha$ ) after incubation with SPIONs. A cytometric bead array (CBA) application was performed as per manufacturer protocol and measured by flow cytometry using the FACSCanto (BD).

\section{ROS assay}

The intracellular formation of ROS was detected using $2^{\prime}, 7^{\prime}$ Dichlorofluorescein diacetate (DCFH-DA, $10 \mu \mathrm{M}$; SigmaAldrich), which binds to the fluorescent dichlorofluorescein by intracellularly reacting with ROS. Thirty minutes after incubation with DCFH-DA, fluorescence was measured by a Tecan Infinite ${ }^{\circledR}$ F200 fluorescent plate reader (Tecan Group Ltd., Maennedorf, Switzerland) using excitation and emission settings of $485 \mathrm{~nm}$ and $535 \mathrm{~nm}$.

\section{Statistical analysis}

Statistical analysis was conducted using a Student's $t$-test (paired, two-tail) with $P<0.05$ considered significant.

\section{Results}

\section{Characterization of UL-D}

The iron concentrations of the UL-D tracer solutions were between $0.22 \mathrm{mmol} / \mathrm{mL}$ and $0.25 \mathrm{mmol} / \mathrm{mL}(12 \mathrm{mg} / \mathrm{mL}$ and $14 \mathrm{mg} / \mathrm{mL}$ ) Fe and were determined by photometry of the Prussian blue iron complex. After several separation and purification steps, the iron concentration was increased to a maximum of $0.25 \mathrm{mmol} / \mathrm{L}$. The hydrodynamic diameter of the SPIONs was determined by dynamic light scattering based on PCCS. UL-D had a hydrodynamic diameter of between $83.5 \mathrm{~nm}$ and $86 \mathrm{~nm}$ whereas Resovist showed variations in the mean hydrodynamic diameter of $60 \mathrm{~nm}$ to $80 \mathrm{~nm}$.
HRTEM measurements of the particles were used for further characterization of the UL-D particle cores. Figure 1 shows particle size distribution. Particle aggregation can be seen as a response to a lack of dextran-coating. This explains why the size of a single nanoparticle could not be determined by HRTEM analysis. The aggregate lengths of $150 \mathrm{~nm}-200 \mathrm{~nm}$ within the nanoparticles appeared to be homogeneous. Another method for estimating the core diameter of UL-D was based on AFM (Figure 2). The image shows a surface structure of dried particles on mica sheets. The dextran coat is dried out, leaving only the surface structure of the iron oxide core. The core diameter of the smaller particles varied between $10 \mathrm{~nm}$ and $17 \mathrm{~nm}$, indicating a homogeneous core size distribution of the particles deemed adequate for MPI. The iron oxide core diameter of UL-D in the concentrated particle solution was measured by MPS. The diameter remained relatively constant over 6 weeks of measurements, varying only between $16 \mathrm{~nm}$ and $18 \mathrm{~nm}$ (data not shown).

To analyze the stability of UL-D, the change in the hydrodynamic diameter of UL-D in DMEM or (A)-DEST was statistically evaluated by PCCS over a 2 week period. Moreover, the influence of the particles in the solutions was analyzed according to their concentration in the solutions. Over 2 weeks, the hydrodynamic diameter of the particles remained very stable (Figure 3 ). No aggregation or cluster formations of UL-D were observed. This stable 2 week interval appeared to be conducive to performing in vivo MPI tests.

\section{SPION toxicity}

To assess SPION biocompatibility, the mitochondrial activity represented by the number of cells was measured using

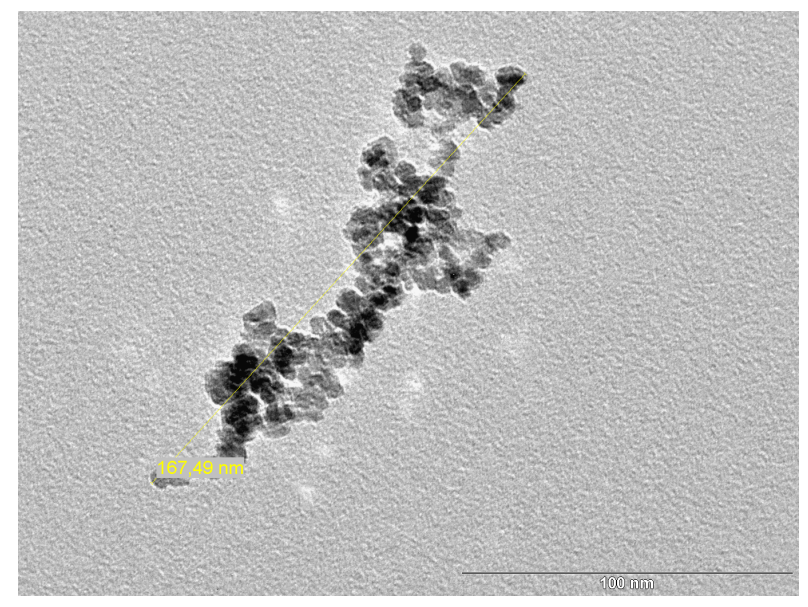

Figure I HRTEM image of UL-Ds' iron core.

Notes: The bar shows the scale in $\mathrm{nm}$ and the yellow line shows the size of the nanoparticle aggregate.

Abbreviations: HRTEM, high-resolution transmission electron microscopy; UL-Ds, University of Luebeck-Dextran coated superparamagnetic nanoparticles. 
A

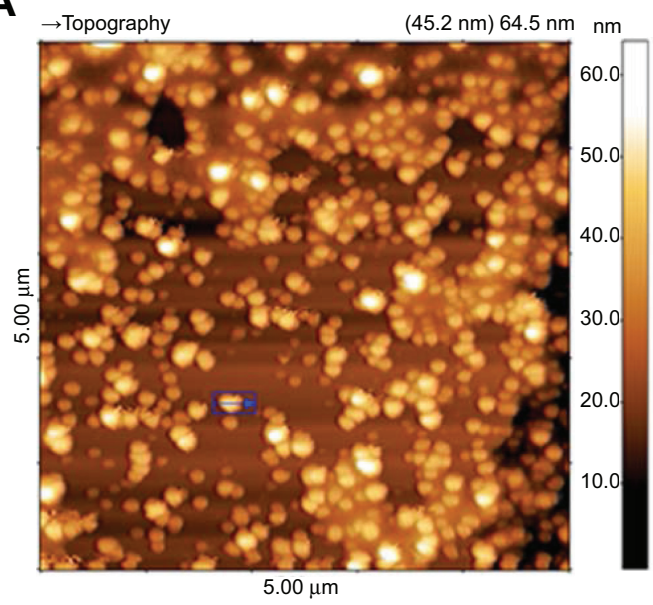

B

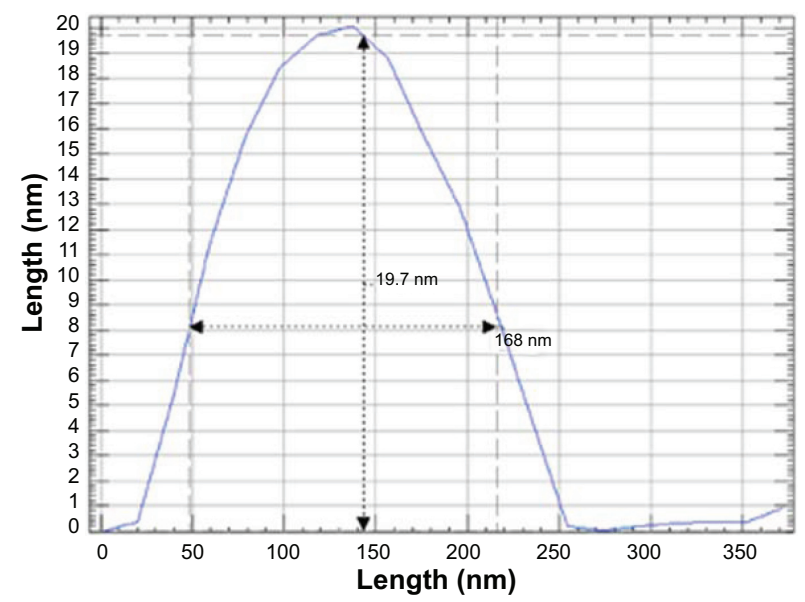

Figure $25 \mu \mathrm{m}$ AFM topographic image of UL-D (A) and AFM height histogram of a single nanoparticle (B).

Notes: Height/length is in $\mathrm{nm}$. The blue box $(\mathbf{A})$ indicates a single nanoparticle used for the histogram.

Abbreviations: AFM, atomic force microscopy; UL-D, University of Luebeck-Dextran coated superparamagnetic nanoparticles.

MTT assay. The absorbance values were used to metabolically quantify viable cells after incubation with SPIONs. We found decreased activity of cellular enzymes of HNSCC cells labeled with UL-D or Resovist nanoparticles (Figure 4). Resovist seemed to have a stronger effect on cells than UL-D. A significant decrease in the absorbance signals and a marked increase in toxicity were measured based on levels of $>0.2 \mathrm{mM} \mathrm{Fe}$ Resovist. This dose-dependent reduction suggests either a diminished number of cells or a lower metabolization of MTT by mitochondrial dehydrogenases.

Using proliferation real-time assay, we confirmed the growth inhibition of SPIONs. The cell index was not reduced under increasing SPION concentrations and incubation times for UL-D (Figure 5). UL-D did not induce growth inhibition and showed a mean doubling time of 20 hours, whereas a decreased cell index was observed after Resovist treatment.
High concentrations of Resovist, especially between $0.9 \mathrm{mM}$ and $1.8 \mathrm{mM} \mathrm{Fe}$, indicated inhibition of cell growth.

\section{Survival of SPION-labeled cells}

To test whether the labeling of HNSCC cells with SPIONs could influence cell viability, cells were analyzed by flow cytometry using an Annexin V-APC/PI method in which viable cells were identified as Annexin and PI-negative, whereas apoptotic cells were pictured as Annexin positive. These cells are an indicator of cell toxicity and are characterized by membrane inversion and loss of asymmetry. Damaged and decayed cells are permeable to PI. Results of UT-SCC-60A and UT-SCC-60B cell viability after treatment for 120 hours and incubation with SPIONs are shown in Figure 6. Flow cytometric analysis showed that UL-D did not change the cell viability of HNSCC cells. Concentrations

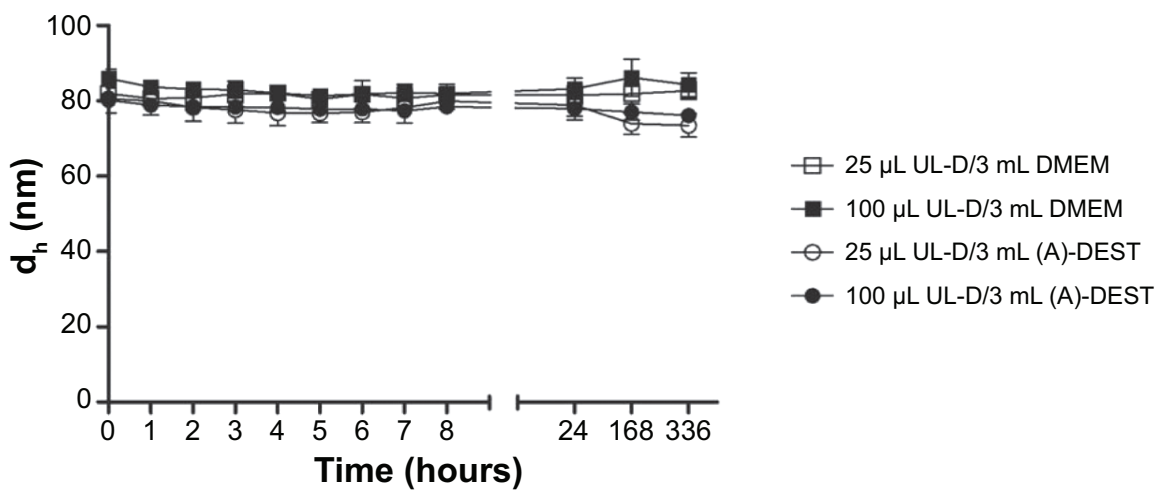

Figure 3 Stability of UL-D in (A)-DEST and cell medium (DMEM) in two different concentrations ( $25 \mu \mathrm{L}$ and $100 \mu \mathrm{L}$ in $3 \mathrm{~mL}$ solution) by PCCS analysis of the hydrodynamic size of UL-D over 336 hours.

Notes: Data are expressed as means of the hydrodynamic diameter in $\mathrm{nm} \pm$ standard deviation from five experiments.

Abbreviations: $d_{h}$, hydrodynamic diameter; DMEM, Dulbecco's Modified Eagle's Medium; PCCS, photon cross correlation spectroscopy; UL-D, University of LuebeckDextran coated superparamagnetic nanoparticles; (A)-DEST, distilled water. 
A

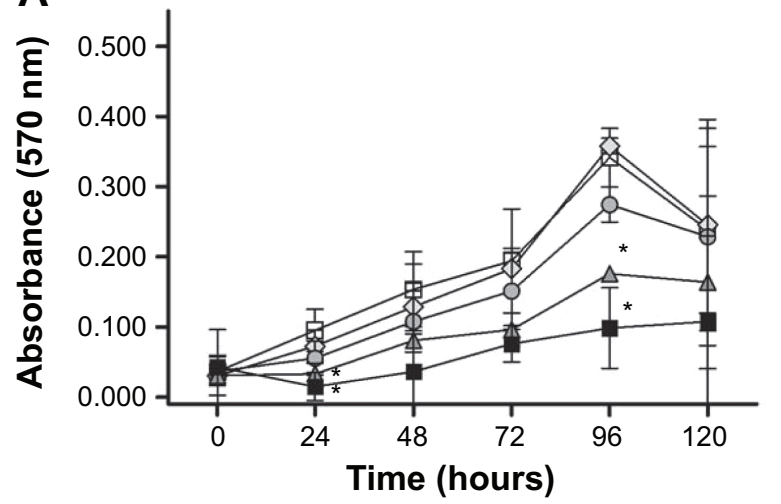

UL-D $\square 0 \mathrm{mM} \mathrm{Fe} \prec 0.2 \mathrm{mM} \mathrm{Fe}$

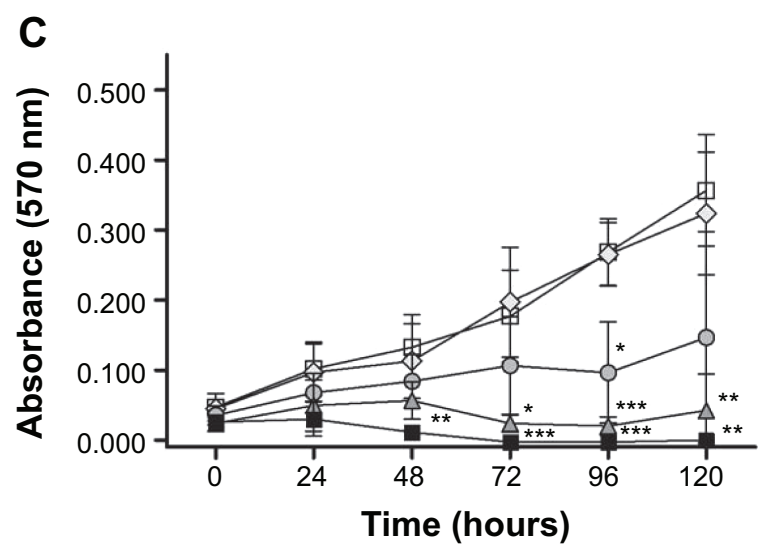

Resovist $\square 0 \mathrm{mM} \mathrm{Fe} \prec 0.2 \mathrm{mM} \mathrm{Fe}$
B

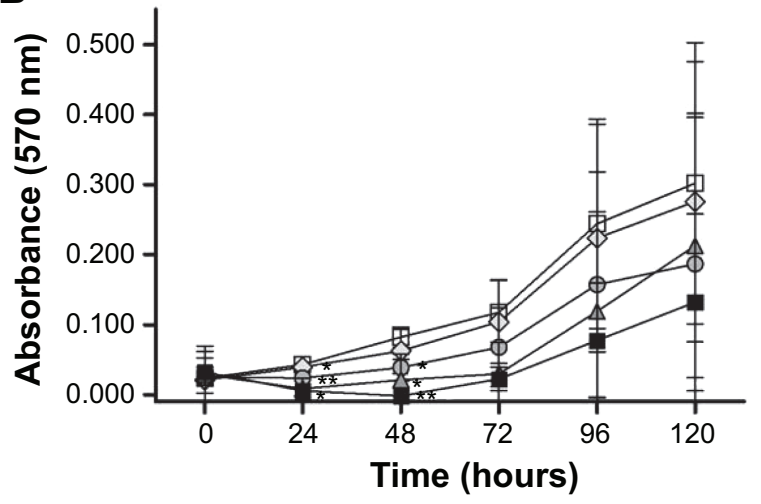

$0.5 \mathrm{mM} \mathrm{Fe} \triangle 0.9 \mathrm{mM} \mathrm{Fe} \rightarrow 1.8 \mathrm{mM} \mathrm{Fe}$

D

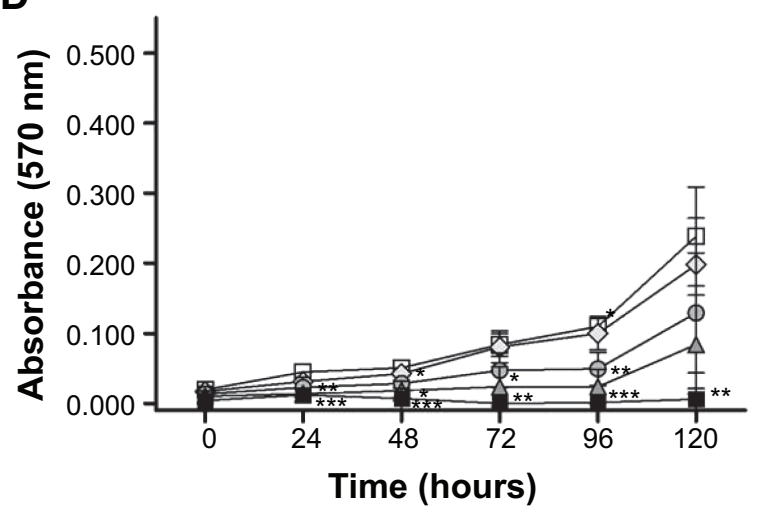

Figure 4 Cytotoxic analysis of SPIONs.

Notes: Metabolic activity of UT-SCC-60A (A and B) and UT-SCC-60B (C and D) with and without exposure to various concentrations ( $0.2 \mathrm{mM}, 0.5 \mathrm{mM}, 0.9 \mathrm{mM}$, $1.8 \mathrm{mM}$ Fe) of UL-D and Resovist ${ }^{\circledR}$ (Bayer Schering Pharma AG, Leverkusen, Germany) over 120 hours using an MTT assay. Data are expressed as absorption means \pm standard deviation of three experiments. Statistical significance compared to unlabeled cells as control. $* P<0.05 ; * * P<0.01 ; * * * P<0.00$ I.

Abbreviations: MTT, 3-(4,5-dimethylthiazol-2-yl)-2,5-diphenyltetrazoliumbromide; UL-D, University of Luebeck-Dextran coated superparamagnetic nanoparticles.

of up to $1.8 \mathrm{mM}$ Fe showed no visible differences in the death rates of UL-D-labeled and unlabeled control cells. In comparison, Resovist negatively affected HNSCC cell viability in a dose-and time-dependent manner. Cell death of the HNSCC cells was attributed to apoptosis but was barely detectable in Fe concentrations of $\geq 0.5 \mathrm{mM}$.

\section{Cellular uptake of UL-D}

We initially examined UL-D uptake of direct fluorescence-labeled UL-D nanoparticles by flow cytometry and microscopy (Figure 7). Fluorescence analysis showed that rhodamine-labeled UL-D could be internalized into HNSCC cells. Microscopy images demonstrated a localization of UL-D in the cytoplasm but not in the nucleus. However, the fluorescent signals were weak and not sensitive enough to perform quantitative analysis or to determine the uptake process. After 24 hours incubation of the HNSCC cells with $0.9 \mathrm{mM}$ and $1.8 \mathrm{mM}$ Fe rhodamine-labeled UL-D, the
FACS histogram profile shifted and showed a labeling rate of $\sim 100 \%$ whereas no fluorescence was found in unlabeled cells. Compared to UT-SCC-60B, a higher fluorescent signal was observed for UT-SCC-60A.

\section{Comparison of SPION internalization}

To compare the magnetic properties of Resovist with UL-D nanoparticles, the magnetic properties of the particles were analyzed by magnetic particle spectroscopy (MPS) before using them for cell experiments. In MPS, the particles are subjected to a sinusoidally varying magnetic field. The magnetization response of the particles, however, is a non-linear periodic signal due to the superparamagnetic properties of the particles. As a result, the time signal of the particle magnetization was a distorted sine wave containing harmonics of the fundamental frequency of the excitation field in the Fourier space. Decay of these harmonics was a quality measure of the particles; specifically, the slower the 


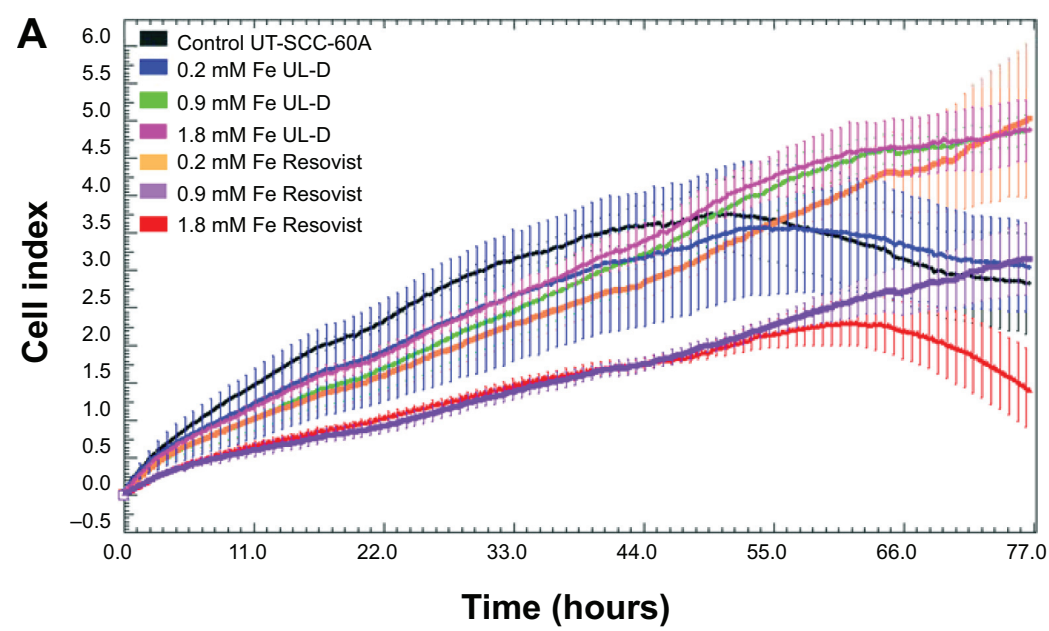

B

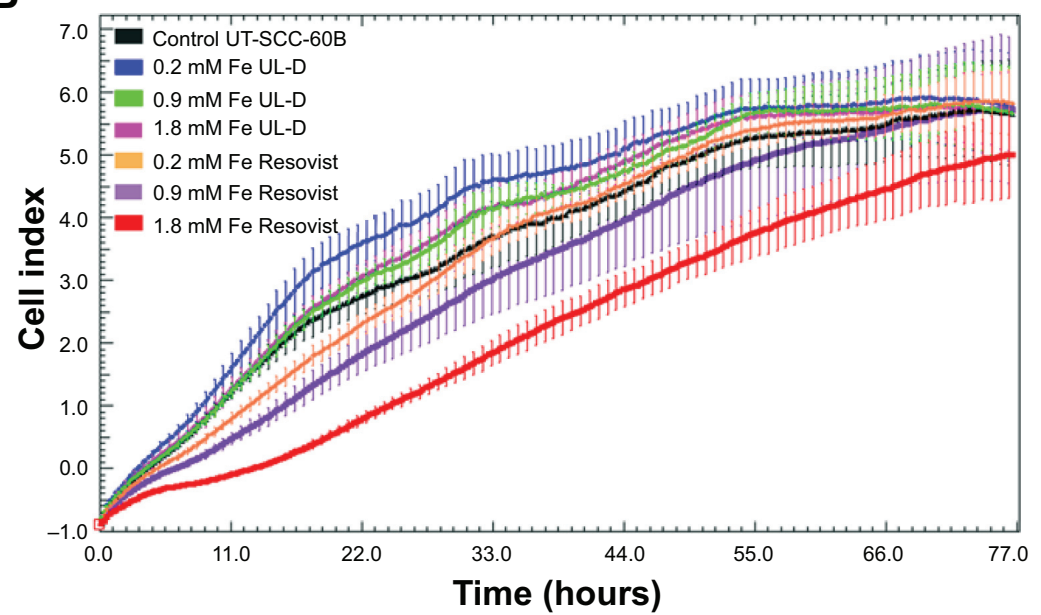

Figure 5 Proliferation of HNSCC cells UT-SCC-60A (A) and UT-SCC-60B (B) with and without exposure to various concentrations (0.2, 0.9, I.8 mM Fe) of UL-D and Resovist ${ }^{\circledR}$ over 72 hours using real-time cell proliferation assay.

Notes: Cell proliferation data represent mean \pm standard deviation of a representative experiment chosen from a series of three independent experiments. In parallel unlabeled cells were conducted as controls. The manufacturer of Resovist ${ }^{\circledR}$ is Bayer Schering Pharma AG, Leverkusen, Germany.

Abbreviations: HNSCC, head and neck squamous cancer cells; UL-D, University of Luebeck-Dextran coated superparamagnetic nanoparticles.

decay the better the particle quality for application in MPI. Since the non-linearity of particle magnetization is related to iron-core diameter, this parameter can be estimated by solving the inverse problem based on the parameters of the Langevin theory. ${ }^{9}$ It can be seen in Figure 8 that UL-D outperformed Resovist. The estimated core diameter of UL-D based on the slope of the MPS measurements was between $10 \mathrm{~nm}$ and $15 \mathrm{~nm}$.

To evaluate nanoparticle uptake, we performed MPS measurements (Figure 8). UT-SCC-60A cells were incubated with either $0.9 \mathrm{mM}$ Resovist or UL-D. To summarize, all measured iron events were low but cells incubated with Resovist showed a higher signal than UL-D-treated cells.

To assess and compare SPION uptake, an immunohistological method was used. Labeled cells were stained for dextran to illustrate the efficient uptake of SPIONs into the cellular lumen of the two HNSCC cell lines. Two hours after their application, the uptake of UL-D and Resovist into both cell lines was initially detected (data not shown), with maximum uptake visible after 24 hours (Figure 9). SPIONs seemed to be unspecifically phagocytized and were localized within the cell in a dose-dependent manner. Uptake efficiency was dependent on the type of SPION. Resovist uptake was much higher than UL-D uptake.

\section{Physiological effects}

To investigate whether the SPIONs were involved in the generation of ROS in HNSCCs, we measured their production using DCFH-DA. In the presence of ROS, a fluorescent form is built that can be detected. None of the nanoparticles showed any indication of causing increased levels of intracellular ROS (Figure 10). Cells incubated with UL-D or Resovist 
A

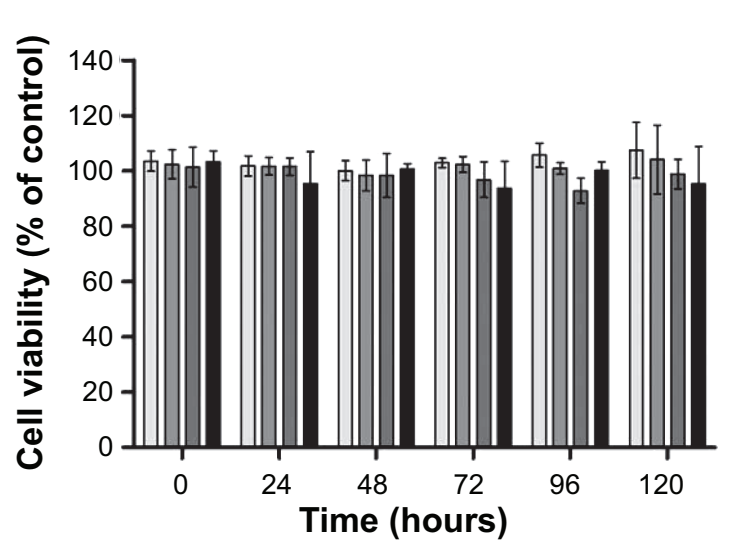

C

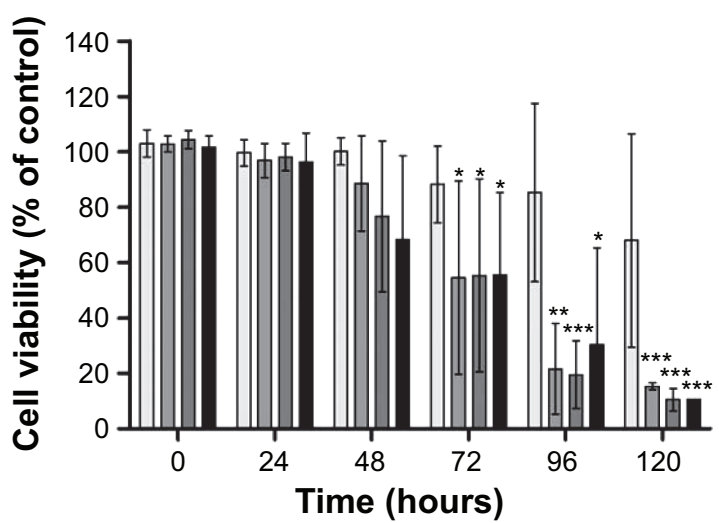

B

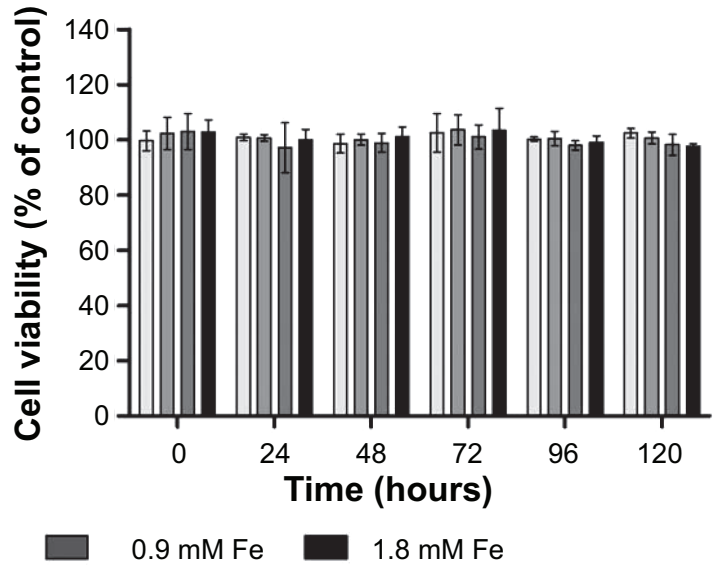

D

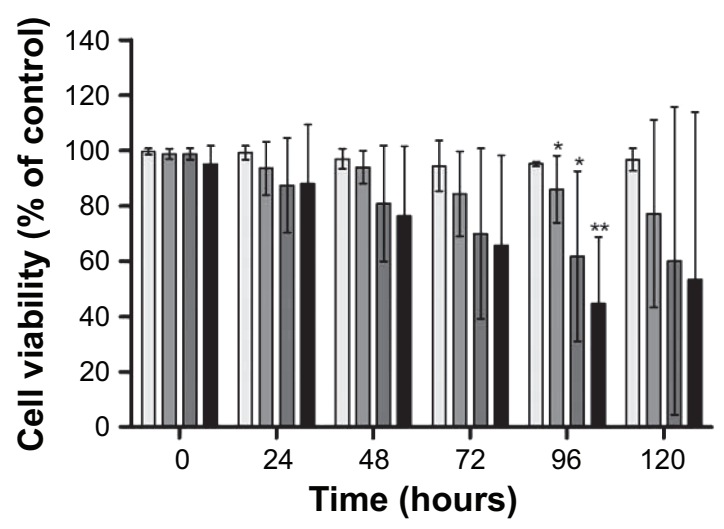

Resovist

$0.2 \mathrm{mM} \mathrm{Fe}$

$0.5 \mathrm{mM} \mathrm{Fe}$

$0.9 \mathrm{mM} \mathrm{Fe}$

$1.8 \mathrm{mM} \mathrm{Fe}$

Figure 6 Cell viability of HNSCC cells UT-SCC-60A (A and C) and UT-SCC-60B (B and D).

Notes: Cell viability was determined using Annexin V-APC/PI staining by flow cytometry after incubation with both types of SPIONs (UL-D and Resovist $\left.{ }^{\circledR}\right)$ at different concentrations $(0.2 \mathrm{mM}, 0.5 \mathrm{mM}, 0.9 \mathrm{mM}, 1.8 \mathrm{mM} \mathrm{Fe})$ over 120 hours. Data are expressed as means \pm standard deviation from three experiments as \% of unlabeled control cells. Statistical significance compared to unlabeled cells as controls. ${ }^{*} P<0.05 ; * * P<0.01$; $* * * P<0.00$ I. The manufacturer of Resovist ${ }^{\circledR}$ is Bayer Schering Pharma AG, Leverkusen, Germany.

Abbreviations: APC, allophycocyanin; PI, propidium iodide; HNSCC, head and neck squamous cancer cells; UL-D, University of Luebeck-Dextran coated superparamagnetic nanoparticles; SPION, superparamagnetic iron oxide nanoparticle.

showed similar mean values of fluorescent units compared to control cells, whereas cells treated with $\mathrm{H}_{2} \mathrm{O}_{2}$ as positive controls depicted ROS induction. There were no instances of oxidative stress caused by SPIONs.

The release of the inflammatory cytokines IL-6, IL-8, IL-1 $\beta$, and TNF- $\alpha$ was analyzed. Cytokines IL-6 and IL-8 are involved in oncogenic processes such as anti-apoptosis, angiogenesis, and metastasis. In human cancer, TNF- $\alpha$ is often dysregulated and plays an important role in systemic inflammation processes. We were able to demonstrate that the expression profiles of IL- 6 , IL-8, and TNF- $\alpha$ were not influenced by the presence of nanoparticles (data not shown). Cytokine IL-1 $\beta$ contributes to tumor invasion and metastasis. Our data clearly showed that incubation with Resovist nanoparticles led to a strongly increased expression of IL-1 $\beta$ in UT-SCC-60A (Figure 11), whereas it had no significant influence on cytokine secretion in UT-SCC-60B. Incubation with UL-D nanoparticles did not affect cell response.

\section{Discussion}

Desired SPION characteristics for use in MPI are narrow particle size and high magnetization response to achieve technical relevance. Until now, no commercially available SPION could provide high spatial resolution and high sensitivity when used with MPI. ${ }^{19}$ The MPI tracer UL-D imparts an optimal homogeneous diameter and ideal size distribution. However, before considering in vivo applications, evaluation of the biocompatibility and uptake efficiency of the nanoparticles is required.

In the current study, we compared the labeling possibilities of UL-D and the pre-established tracer Resovist for MPI. SPION uptake efficiencies and toxicities were assessed 


\section{A}

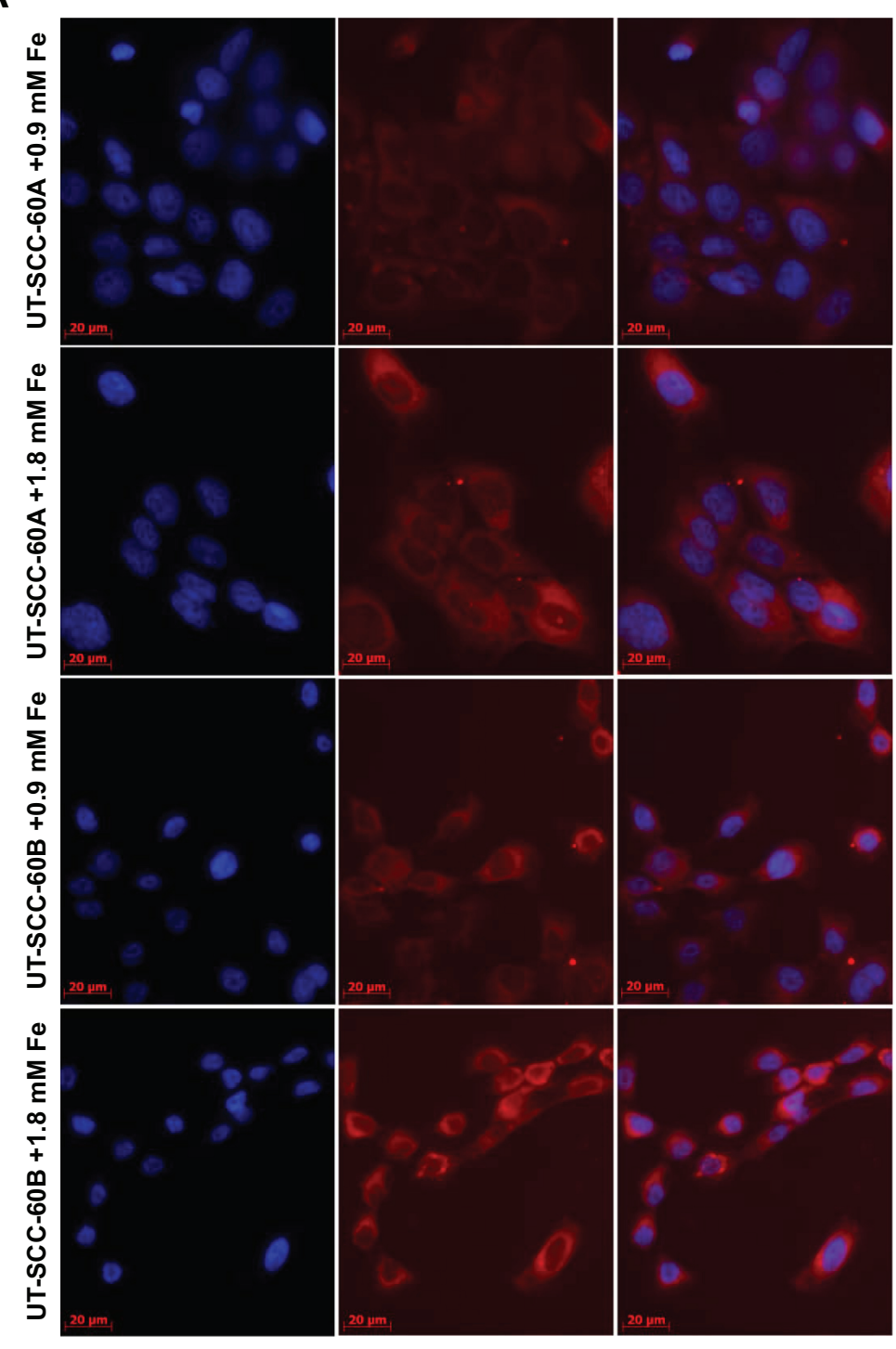

B
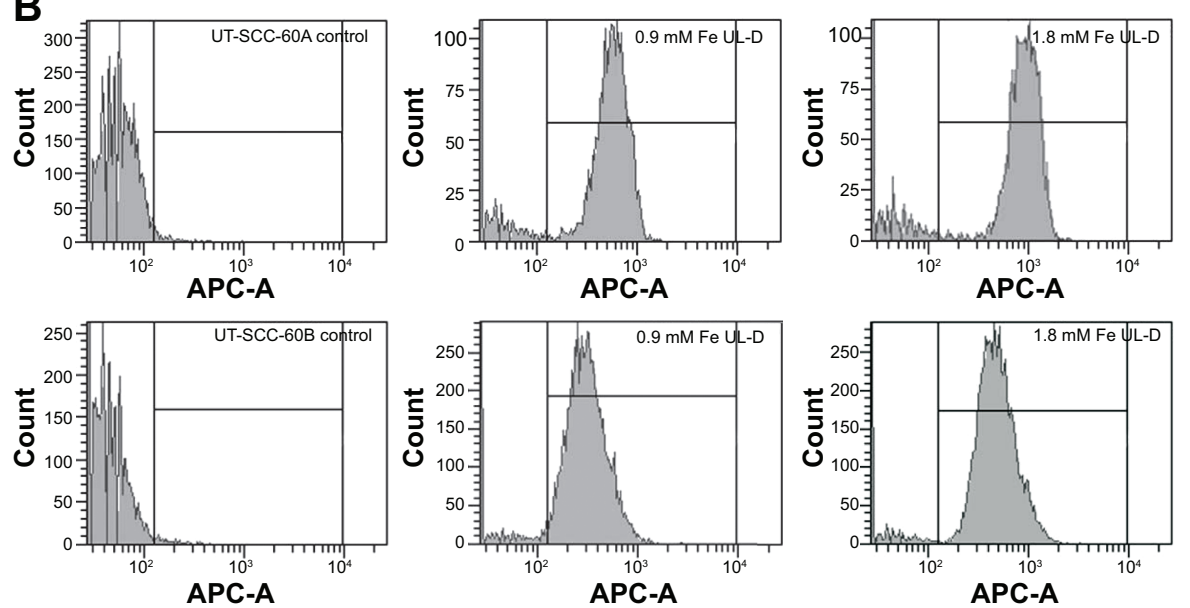

Figure 7 Cellular uptake of UL-D-labeled tumor cells.

Notes: Nanoparticle internalization into HNSCCs was analyzed in UT-SCC-60A and UT-SCC-60B cells with rhodamine-labeled UL-D (0.9 mM and I.8 mM Fe) after 24 hours. (A) Microscopy analysis of labeled and unlabeled cells. Nuclei were counterstained with DAPI. (B) Fluorescent histogram profile of labeled cells compared to unlabeled control cells by flow cytometry. Each $\mathrm{x}$-axis shows a log scale of the fluorescence intensity.

Abbreviations: HNSCC, head and neck squamous cancer cells; APC, allophycocyanin; DAPI, 4',6-diamidino-2-phenylindole; UL-D, University of Luebeck-Dextran coated superparamagnetic nanoparticles. 
A

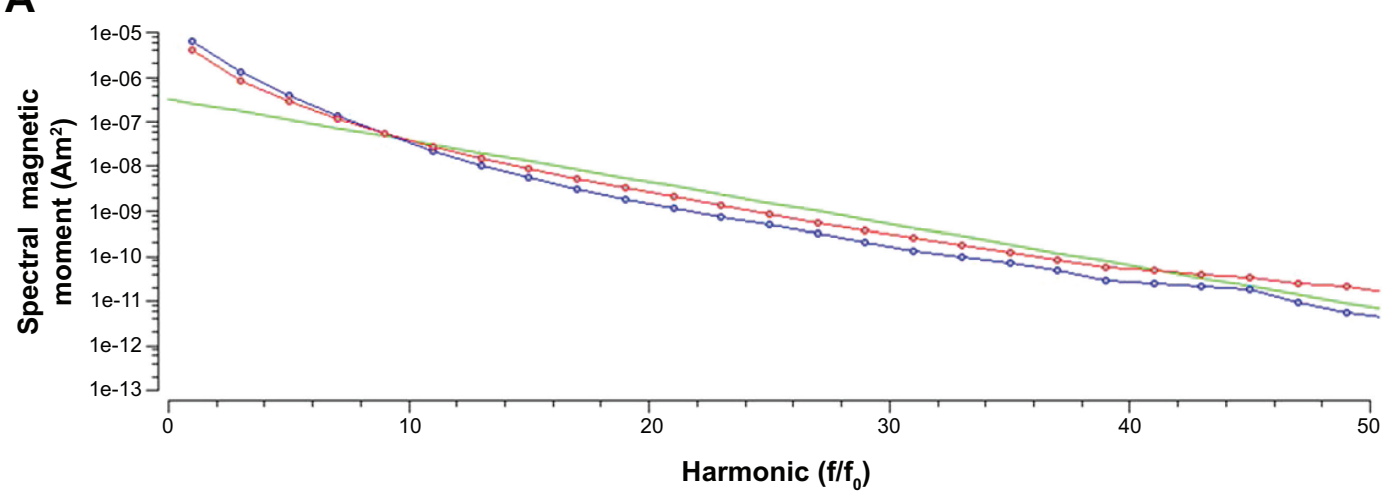

B
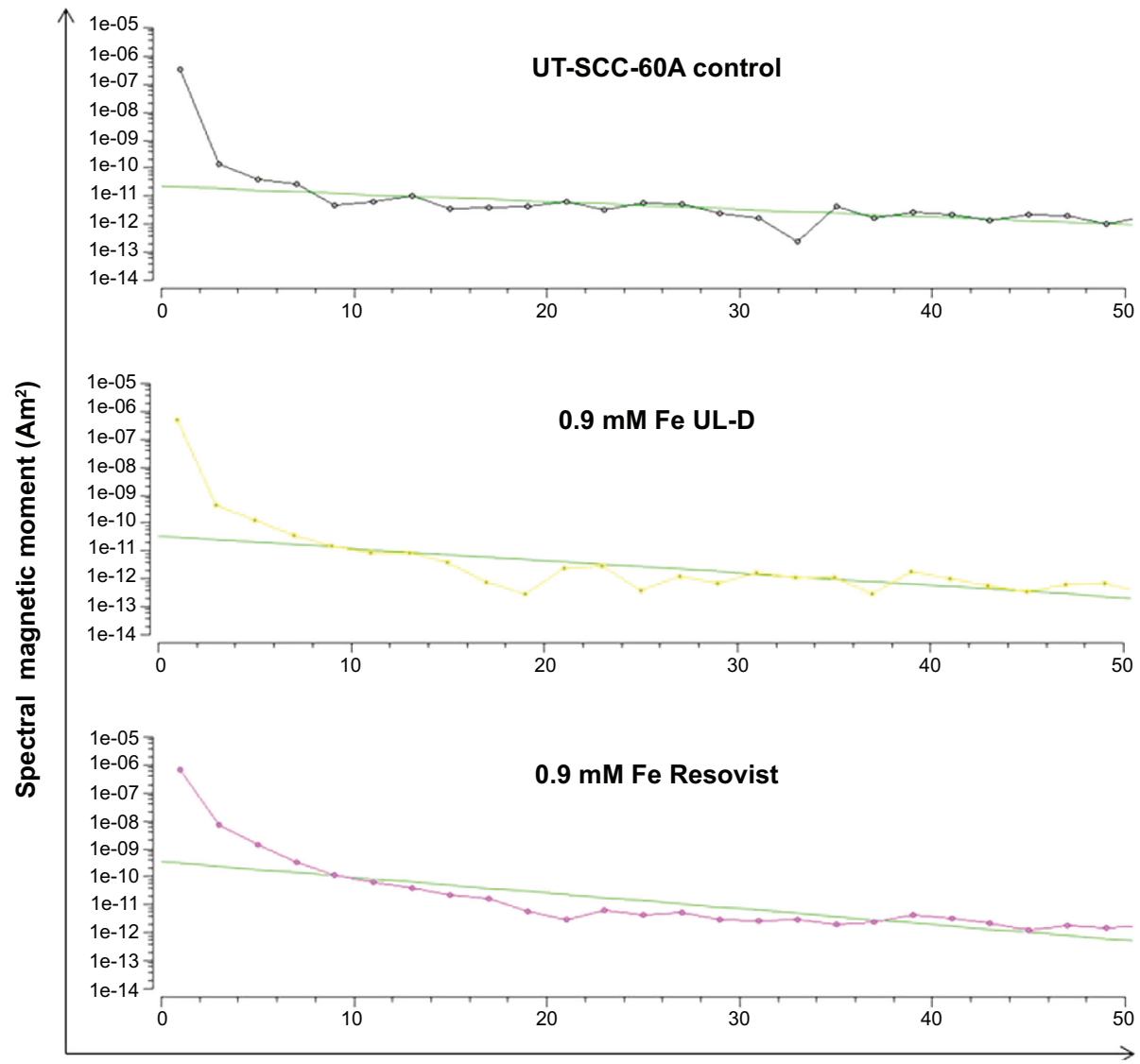

Harmonic $\left(\mathrm{f} / \mathrm{f}_{0}\right)$

Figure 8 (A) Decay of the harmonics for Resovist ${ }^{\circledast}$ (blue) and UL-D (red). (B) MPS measurements of UT-SCC-60A cells after 2 hours incubation with 0.9 mM Fe UL-D or Resovist ${ }^{\circledR}$.

Notes: The manufacturer of Resovist ${ }^{\circledR}$ is Bayer Schering Pharma AG, Leverkusen, Germany.

Abbreviations: $\mathrm{f} / \mathrm{fo}$, frequency/fundamental frequency; MPS, magnetic particle spectrometer; UL-D, University of Luebeck-Dextran coated superparamagnetic nanoparticles.

using HNSCC cell lines. Both SPIONs were internalized into tumor cells, although Resovist was more efficiently taken up, which was confirmed by MPS and microscopy. Cell viability and proliferation, formation of ROS, and release of cytokines IL-1 $\beta$, IL-6, IL-8, and TNF- $\alpha$ were not affected in any way by UL-D labeling. In fact, MTT assay showed that the metabolic activity of HNSCC cells decreased in a dosedependent manner. Resovist also negatively influenced cell proliferation and viability, as well as metabolic activity. The presence of oxidative stress and the release of TNF- $\alpha$, IL- 6 , and IL-8 showed the same characteristics as the control cells. However, a change in IL-1 $\beta$ concentration was observed in the supernatants of UT-SCC-60A cells labeled with Resovist. These data confirm that Resovist leads to a stronger alteration of HNSCC's biological properties compared to UL-D. Thus, UL-D nanoparticles showed better biocompatibility whereas 


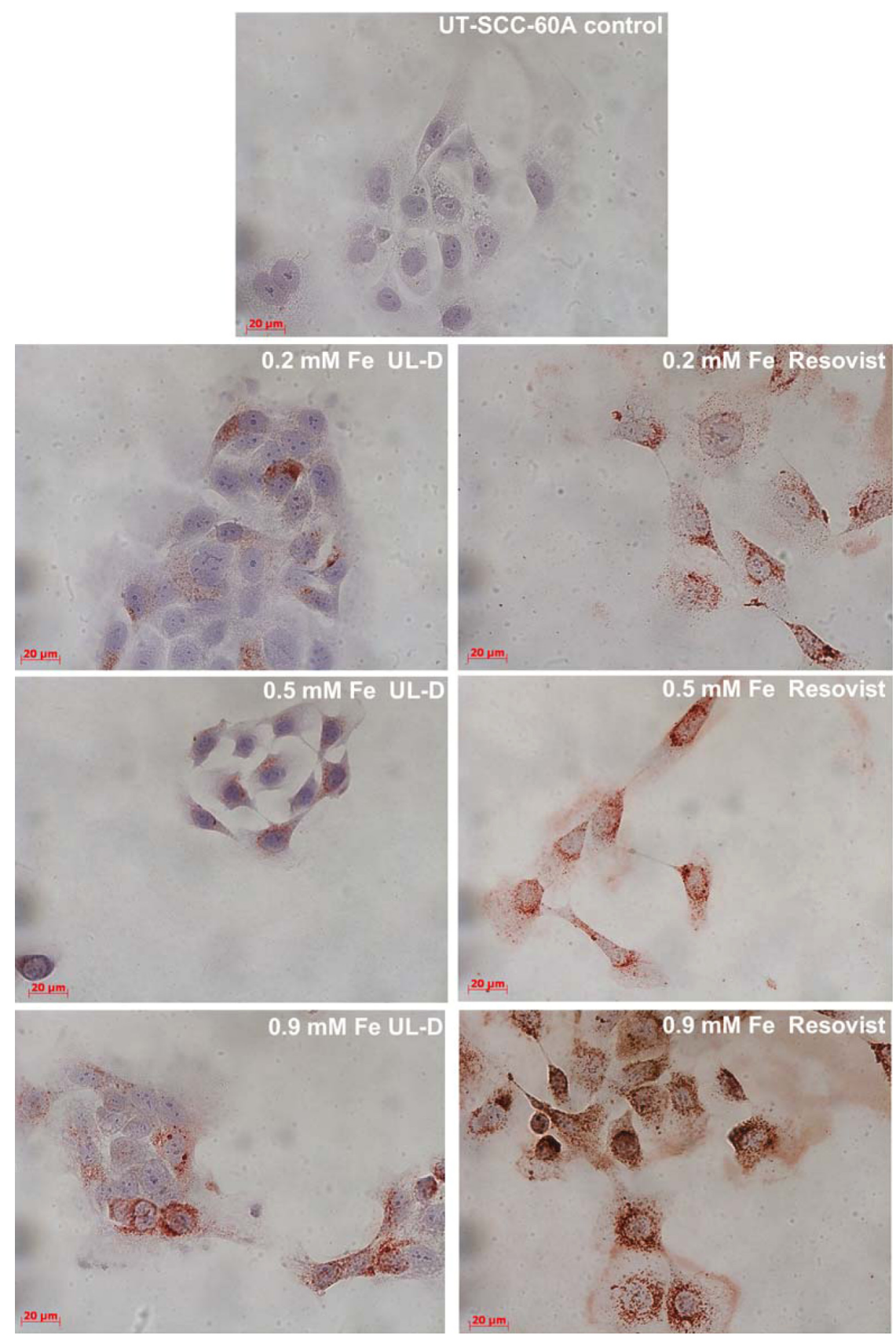

Figure 9 Cellular uptake of UL-D and Resovist ${ }^{\circledR}$-labeled tumor cells.

Notes: UT-SCC-60A cells were incubated with $0.2 \mathrm{mM}, 0.5 \mathrm{mM}$, and $0.9 \mathrm{mM}$ Fe UL-D and Resovist ${ }^{\circledR}$ for 24 hours, stained with anti-dextran, and analyzed by microscopy. Nuclei staining by H\&E. The manufacturer of Resovist ${ }^{\circledR}$ is Bayer Schering Pharma AG, Leverkusen, Germany.

Abbreviations: H\&E, hematoxylin and eosin; UL-D, University of Luebeck-Dextran coated superparamagnetic nanoparticles.

the higher unspecific Resovist uptake by HNSCC was linked to negative biological influences. Instead, UL-D depicted a lesser internalization thought sufficient for MPI measurements.

Contrast agent iron oxide nanoparticles have been used for over 50 years. ${ }^{29}$ Important characteristics are size and surface of the nanoparticles as well as surface chemistry. Nanoparticle requirements for use in biomedical applications are high magnetization value, size $<100 \mathrm{~nm}$, narrow particle size distribution, and specific surface coating. ${ }^{30}$ A common method for synthesizing magnetic nanoparticles is chemical synthesis, in particular a co-precipitation of iron oxide in an alkaline solution. ${ }^{20,31}$ Aqueous solution as a suspension medium offers stability to the SPIONs by means of ion interactions. The ability to agglomerate is reduced but not completely prevented. ${ }^{20}$ Nanoparticles of $\sim 100 \mathrm{~nm}$ have different magnetic properties than the corresponding bulk 
A

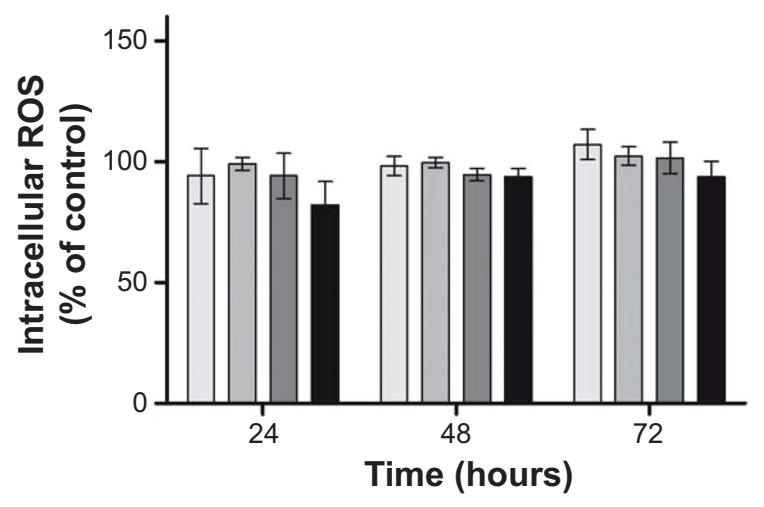

B

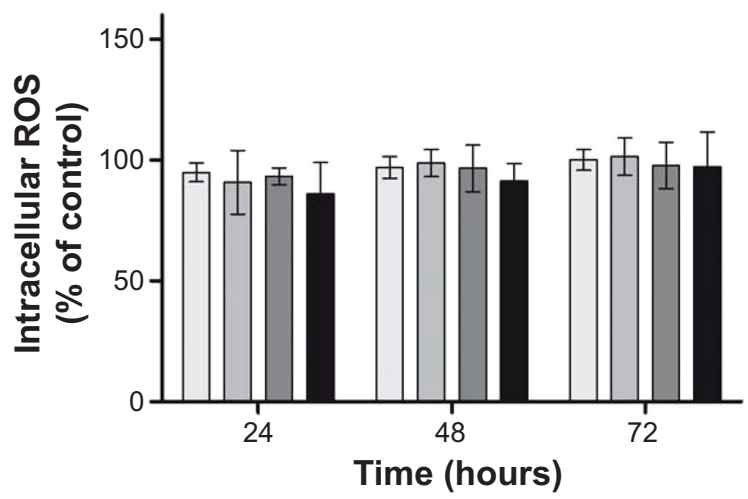

UL-D $\square 0.2 \mathrm{mM}$ Fe $\square 0.5 \mathrm{mM}$ Fe $\square 0.9$ mM Fe $\square 1.8 \mathrm{mM} \mathrm{Fe}$
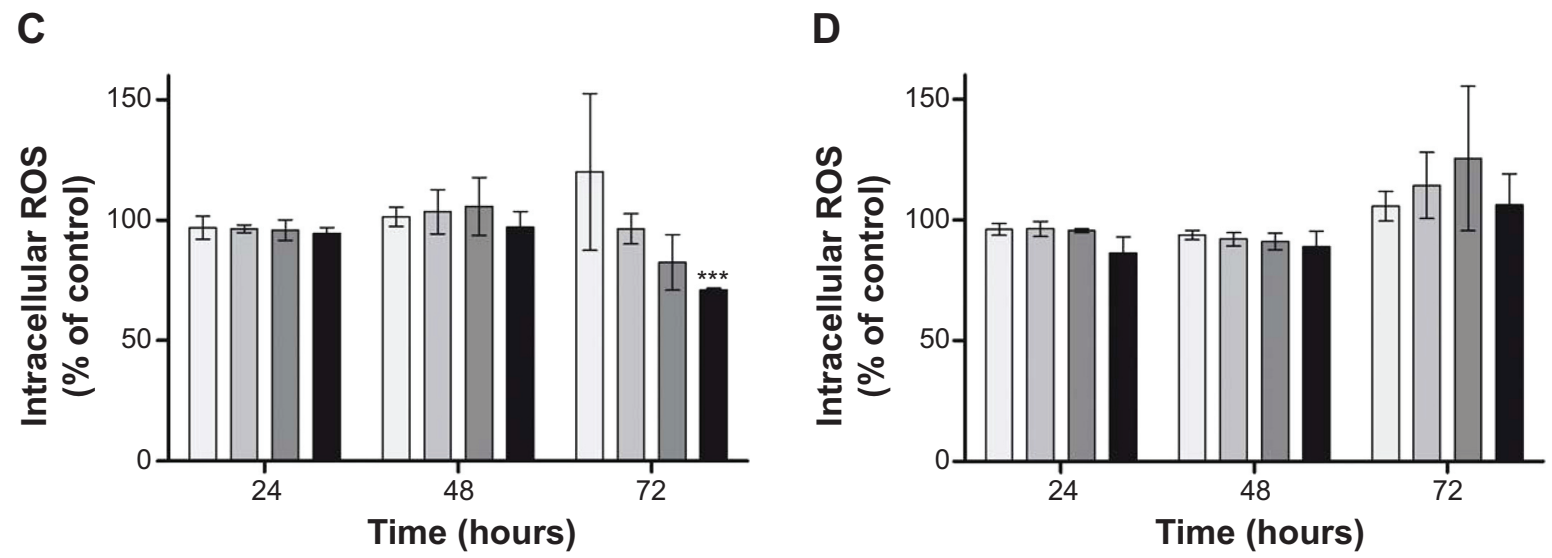

Resovist insert ${ }^{\circledR} \square 0.2$ mM Fe $\square 0.5$ mM Fe $\square 0.9$ mM Fe $\square 1.8$ mM Fe

Figure 10 Intracellular ROS production in UT-SCC-60A (A and B) and UT-SCC-60B (C and D) cells after exposure to various concentrations of SPIONs (0.2 mM, $0.5 \mathrm{mM}$, $0.9 \mathrm{mM}, 1.8 \mathrm{mM}$ Fe), UL-D and Resovist ${ }^{\circledR}$ for 24 hours, 48 hours, and 72 hours, respectively.

Notes: Each bar represents the average value of three independent experiments \pm standard deviation shown as \% of control. Statistical significance compared to unlabeled cells as control. ${ }^{* * * P}<0.001$. The manufacturer of Resovist ${ }^{\circledR}$ is Bayer Schering Pharma AG, Leverkusen, Germany.

Abbreviations: ROS, reactive oxygen species; UL-D, University of Luebeck-Dextran coated superparamagnetic nanoparticles; SPION, superparamagnetic iron oxide nanoparticle.

material. Superparamagnetic materials have properties that are characteristic of paramagnetic substances and ferromagnetic materials. If there is no external field applied, superparamagnetic materials have no permanent arrangement of their elementary magnetic dipoles. Then again, these superparamagnetic materials have a high magnetic susceptibility to an external magnetic field. Superparamagnetic behavior can only be observed when the magnetic domains are physically separated and do not interact with each other. We initially characterized the UL-D core; without a coating, the nanoparticles aggregated. Core diameters were between $10 \mathrm{~nm}$ and $17 \mathrm{~nm}$ as determined by AFM and between $16 \mathrm{~nm}$ and $18 \mathrm{~nm}$ as measured by MPS; they displayed a homogeneous core comparison to other SPIONs. ${ }^{32,33}$

Uncoated particles can also induce toxicity whereas coated particles are more biocompatible and prevent aggregation. ${ }^{10}$ In the case of polymer-coated SPIONs, it was shown that they had the least impact on cell viability and cellular function. ${ }^{34}$ The widespread coating material dextran was used to coat the UL-D nanoparticles. For this purpose, iron ions were precipitated in the presence of dextran. Dextran stabilizes the colloidal solution, thereby creating many possibilities for further modifications of the surface..$^{35,36}$ To use SPIONs in biomedical applications, they should not exceed a certain size. The hydrodynamic diameter needs to be as small as possible to allow an unhindered circulation in the blood stream after injection of magnetic particles. The hydrodynamic diameter of UL-D was between $83.5 \mathrm{~nm}$ and $86 \mathrm{~nm}$, which turned out to be stable for over 2 weeks. According to size classification, the nanoparticles belong to standardsize SPIONs, which have an overall diameter of $50 \mathrm{~nm}$ to $150 \mathrm{~nm}$. Particle size is important for intracellular uptake and 
A

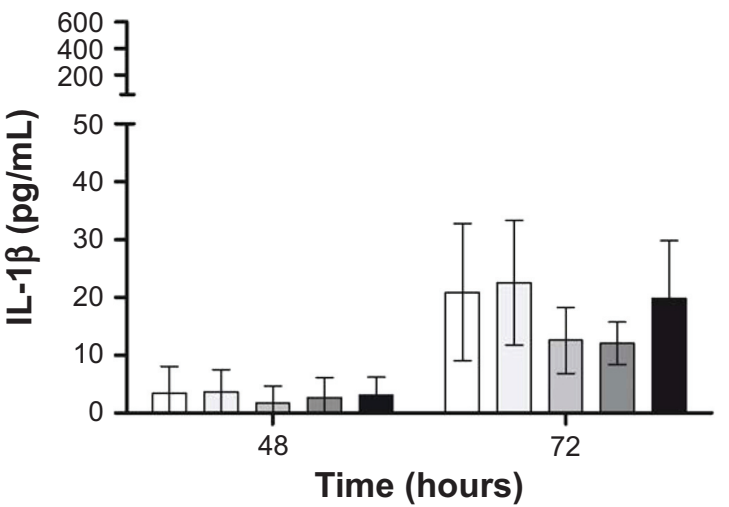

UL-D

C

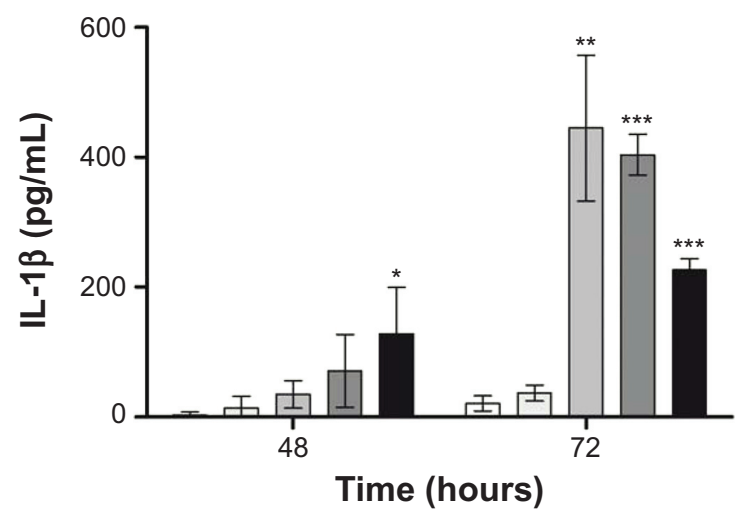

B

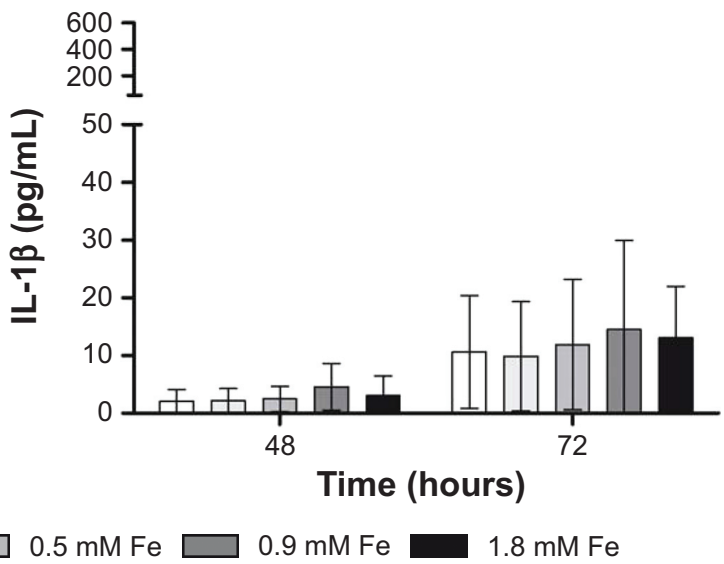

D

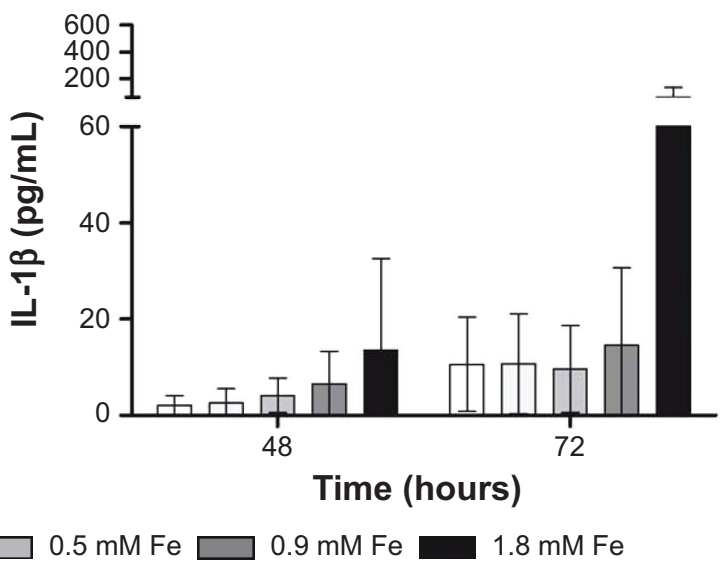

Figure II IL-I $\beta$ expression patterns in HNSCC supernatants UT-SCC-60A (A and B) and UT-SCC-60B (C and D) labeled with Resovist ${ }^{\circledR}$ and UL-D for 48 hours and 72 hours, respectively, by CBA Bead assay.

Notes: Samples were analyzed by flow cytometry and data are expressed as IL-I $\beta$ concentration in pg/mL and means \pm standard deviation of three experiments. Statistical significance compared to unlabeled cells as controls. $* P<0.05$; $* * P<0.01$; *** $P<0.00$ I. The manufacturer of Resovist ${ }^{\circledR}$ is Bayer Schering Pharma AG, Leverkusen, Germany. Abbreviations: CBA, cytometric bead assay; HNSCC, head and neck squamous cancer cells; IL, interleukin; UL-D, University of Luebeck-Dextran coated superparamagnetic nanoparticles.

elimination from the body. SPIONs of $>200 \mathrm{~nm}$ diameter are captured by the spleen and liver, whereas nanoparticles of $<10 \mathrm{~nm}$ are selectively filtered by the renal system and thus eliminated from the body. ${ }^{37}$

An advantage of dextran as a coating is its long plasma half-life because it enhances blood circulation time. Dextran is a polysaccharide polymer mostly used because of its biocompatibility. Dextran-coated SPIONs have been shown to accumulate in various types of cells, including cancer cells, and have been used in clinical settings for a long time. ${ }^{38-41}$ This process can be quick; that is, labeling takes only a few minutes. The nanoparticles were internalized depending on tumor cell size and morphology, which led to widespread heterogeneity. ${ }^{42-45}$ For instance, some cancer cells solely internalized during division. ${ }^{46}$

As opposed to dextran, Resovist is coated with carboxydextran and is a liver-specific magnetic resonance contrast agent. It is available in a solution that contains substances that stabilize nanoparticles for at least 3 years. It is accumulated by phagocytosis in the cells of the reticuloendothelial system of the liver. This particular feature enables the diagnostic detection of small liver lesions, liver metastases, and small differentiated liver tumors. ${ }^{47-49}$ In the current study, we showed a higher internalization of Resovist compared to UL-D in the HNSCC cells. The surface materials (ie, UL-D or Resovist) seemed to be responsible for the varying unspecific uptake efficiency. A previous study described that carboxydextran-coated nanoparticles appeared to be more frequently internalized by macrophages than dextrancoated SPIONs. In addition, there was no influence on cell activation. $^{50,51}$ It could be possible that nanoparticles were recognized as a foreign substance followed by activation of an immune cascade and secretion of diverse cytokines. ${ }^{52}$ In the current study, cytokine IL-1 $\beta$ was more efficiently 
secreted after exposure to Resovist whereas the release of IL-6, IL-8, and TNF- $\alpha$ were not influenced. It was shown that high concentrations of Resovist $(>100 \mu \mathrm{g} / \mathrm{mL})$ resulted in an increase in secretion and mRNA expression of proinflammatory cytokines IL- 6 , IL- $1 \beta$, and TNF- $\alpha$ in murine peritoneal macrophages ${ }^{53}$ Ferumoxide in a concentration of $500 \mu \mathrm{g} / \mathrm{mL}$ has been shown to also increase IL-1 production in mouse peritoneal macrophages. ${ }^{54}$ Other studies have not observed increased release of cytokines. ${ }^{51,55}$

Our in vitro study suggests that UL-D nanoparticles are biosafe and biocompatible but in vivo experiments need to be performed. The remaining question is what happens after SPION use. Because of their size and coating, the particles are internalized into tissues and organs where they can impact cellular processes and pathways. ${ }^{56}$ Further experiments are necessary to confirm whether UL-D nanoparticles influence and impact human biological properties.

MPI is still in its early stages of development and there is evidence of its many potential applications. One possible application is in the diagnosis of diseases by identifying through imaging various illnesses that involve alterations of organs and tissue. ${ }^{57}$ Early detection of tumor cells by MPI using tracers that accumulate in the cells is possible. ${ }^{58}$ Patients could benefit from more detailed MPI measurements of primary tumor cells and metastatic tissue. The advantages for diagnosis and therapy would be immense.

In addition, detection of lymph node metastases would be possible due to SPIONs' internalization by macrophages and their transportation to lymph nodes. ${ }^{59}$ Compared to normal lymph nodes, metastasized lymph nodes lack macrophages. Imaging is of great importance for staging of tumors since it affects prognosis and allows therapeutic regimes to be optimized. ${ }^{18,60}$ MPI enables visualization of UL-D nanoparticles with high sensitivity and resolution, thus enabling evaluation of the efficiency and tolerance of the nanoparticles. Since neither therapy nor diagnostics of HNSCC have changed during the past few years, MPI represents a new, effective, and innovative imaging approach with great potential for future improvement of diagnostic strategies. However, molecular diagnosis and detection of cancer by optical fitting imaging is only one possible application. ${ }^{61} \mathrm{SPIONs}$ can also be heated and used in hyperthermia therapy. ${ }^{62}$

Quantitative imaging of SPION distribution is possible with MPI, and can increase treatment quality and safety. Furthermore, MPI could provide images that show concentrations and temperature of SPIONs. ${ }^{19}$ In addition to these medical applications, MPI as a contrast agent is a useful tool for cell tracking. MPI visualizes tracer distribution by detecting nonlinear response and can thus be used to track the migration of SPION-labeled cells. The proliferation and migration of these transplanted labeled cells can be monitored in vivo. ${ }^{63}$ In the current study, SPIONs were easily labeled with UL-D because of their natural characteristic to internalize nanoparticles. An MPI scanner for animal use should be ready for use in the near future. Our goal is to trace the migration of UL-D-labeled cells in mice. As a different application, coating of UL-D could be further functionalized with biomolecules for use in other biological applications. Antibodies, peptides, small molecules, and targeting ligands can be bound, and internalization the SPIONs or attachment to the cell surface can be used for cell labeling. ${ }^{21}$ These well-suited SPIONs could also be utilized to detect specific cell subpopulations and classify patients. Such a personalized treatment for HNSCC patients could improve clinical management and outcomes.

\section{Conclusion}

In summary, we have demonstrated that UL-D nanoparticles are biocompatible, have good superparamagnetic behavior, and are suitable for tracer-based MPI technologies. HNSCCs could be labeled with UL-D nanoparticles since they are taken up unspecifically; labeled cells were measured by MPS. In addition, UL-D particles seemed to be more effective than Resovist as a contrast agent. Our study demonstrated that MPI and corresponding UL-D nanoparticles offer a promising tool for in vivo cancer research and innovative diagnostic and therapeutic approaches.

\section{Acknowledgments}

BW acknowledges the financial support by the intramural research funding of the Department of Medicine at the University of Luebeck (Focus program SPP III Biomedical Engineering - Imaging in Disease) and the Rudolf Bartling Stiftung.

\section{Disclosure}

The authors report no conflicts of interest in this work.

\section{References}

1. Tong L, Zhao M, Zhu S, Chen J. Synthesis and application of superparamagnetic iron oxide nanoparticles in targeted therapy and imaging of cancer. Front Med. 2011;5(4):379-387.

2. Gleich B, Weizenecker J. Tomographic imaging using the nonlinear response of magnetic particles. Nature. 2005;435(7046):1214-1217.

3. Buzug TM, Bringout G, Erbe M, et al. Magnetic particle imaging: introduction to imaging and hardware realization. Z Med Phys. 2012; 22(4):323-334.

4. Weizenecker J, Gleich B, Rahmer J, Dahnke H, Borgert J. Threedimensional real-time in vivo magnetic particle imaging. Phys Med Biol. 2009;54(5):L1-L10. 
5. Sattel TF, Knopp T, Biederer S, et al. Single-sided device for magnetic particle imaging. J Phys D Appl Phys. 2009;42(2).

6. Goodwill PW, Tamrazian A, Croft LR, et al. Ferrohydrodynamic relaxometry for magnetic particle imaging. Appl Phys Lett. 2011;98(26). ${ }^{1}$

7. Buzug TM. Magnetic Particle Imaging: Principles and Clinical Application. In: Alexiou C, editors. Nanomedicine - Basic and Clinical Application in Diagnostics and Therapy. Vol 2. Erlangen: Karger Publishers; 2011:88-95.

8. Eberbeck D, Wiekhorst F, Wagner S, Trahms L. How the size distribution of magnetic nanoparticles determines their magnetic particle imaging performance. Appl Phys Lett. 2011;98(18).

9. Biederer S, Knopp T, Sattel TF, et al. Magnetization response spectroscopy of superparamagnetic nanoparticles for magnetic particle imaging. J Phys D Appl Phys. 2009;42(20): Article ID 205007.

10. Ai J, Biazar E, Jafarpour M, et al. Nanotoxicology and nanoparticle safety in biomedical designs. Int J Nanomedicine. 2011;6:1117-1127.

11. Jeng HA, Swanson J. Toxicity of metal oxide nanoparticles in mammalian cells. J Environ Sci Health A Tox Hazard Subst Environ Eng. 2006;41(12):2699-2711.

12. Nel A, Xia T, Madler L, Li N. Toxic potential of materials at the nanolevel. Science. 2006;311(5761):622-627.

13. Singh N, Jenkins GJ, Asadi R, Doak SH. Potential toxicity of superparamagnetic iron oxide nanoparticles (SPION). Nano Rev. 2010;1 Epub 2010 Sep 21.

14. Toyokuni S. Iron and carcinogenesis: from Fenton reaction to target genes. Redox Rep. 2002;7(4):189-197.

15. Mahmoudi M, Simchi A, Milani AS, Stroeve P. Cell toxicity of superparamagnetic iron oxide nanoparticles. J Colloid Interface Sci. 2009; 336(2):510-518.

16. Borgert J, Schmidt JD, Schmale I, et al. Fundamentals and applications of magnetic particle imaging. J Cardiovasc Comput Tomogr. 2012;6(3): 149-153.

17. Haegele J, Rahmer J, Gleich B, et al. Magnetic particle imaging: visualization of instruments for cardiovascular intervention. Radiology. 2012;265(3):933-938.

18. Leemans CR, Braakhuis BJ, Brakenhoff RH. The molecular biology of head and neck cancer. Nat Rev Cancer. 2011;11(1):9-22.

19. Du Y, Lai PT, Leung CH, Pong PW. Design of superparamagnetic nanoparticles for magnetic particle imaging (MPI). Int J Mol Sci. 2013; 14(9):18682-18710.

20. Massart R. Preparation of aqueous magnetic liquids in alkaline and acidic media. IEEE Transactions on Magnetics. 1981;17(2): $1247-1248$

21. Gupta AK, Gupta M. Synthesis and surface engineering of iron oxide nanoparticles for biomedical applications. Biomaterials. 2005;26(18): 3995-4021.

22. Bain BJ. Blood cells: a practical guide. 4th ed. Bain B editor. Malden, Mass: Oxford. Wiley; 2007.

23. Adhikamsetty RK, Jonnalagadda SB. Kinetics and mechanism of prussian blue formation. Bull Chem Soc Ethiop. 2009;23(1):47-54.

24. Xu R. Particle characterization. Light scattering methods. Dordrecht; London: Kluwer Academic; 2000.

25. Mishchenko MI, Travis LD, Lacis AA. Scattering, Absorption, And Emission of Light by Small Particles. Cambridge: Cambridge University Press; 2002.

26. Morris VJ, Kirby AR, Gunning AP. Atomic Force Microscopy for Biologists. 2nd ed. London: Imperial College Press; 2010.

27. Reimer P, Rummeny EJ, Daldrup HE, et al. Clinical results with Resovist: a phase 2 clinical trial. Radiology. 1995;195(2):489-496.

28. Christopher D. Lansford, Reidar Grenman, Henning Bier, et al. Human Cell Culture: Springer Netherlands; 2002.

29. Gilchrist RK, Medal R, Shorey WD, Hanselman RC, Parrott JC, Taylor CB. Selective inductive heating of lymph nodes. Ann Surg. 1957; 146(4):596-606.

30. Laurent S, Forge D, Port M, et al. Magnetic iron oxide nanoparticles: synthesis, stabilization, vectorization, physicochemical characterizations, and biological applications. Chem Rev. 2008;108(6):2064-2110.
31. Berkovskii BM, Bashtovoi VG. Magnetic fluids and applications handbook. New York; Wallingford: Begell House; 1996.

32. Ferguson RM, Minard KR, Krishnan KM. Optimization of nanoparticle core size for magnetic particle imaging. J Magn Magn Mater. 2009;321(10):1548-1551.

33. Buzug TM, Borgert Jr. Magnetic particle imaging: a novel SPIO nanoparticle imaging technique. Heidelberg; London: Springer; 2012.

34. Gupta AK, Curtis AS. Surface modified superparamagnetic nanoparticles for drug delivery: interaction studies with human fibroblasts in culture. J Mater Sci Mater Med. 2004;15(4):493-496.

35. Thorek DL, Chen AK, Czupryna J, Tsourkas A. Superparamagnetic iron oxide nanoparticle probes for molecular imaging. Ann Biomed Eng. 2006;34(1):23-38.

36. Berry CC, Curtis ASG. Functionalisation of magnetic nanoparticles for applications in biomedicine. J Phys D Appl Phys. 2003;36(13): R198-R206.

37. Thorek DL, Chen AK, Czupryna J, Tsourkas A. Superparamagnetic iron oxide nanoparticle probes for molecular imaging. Ann Biomed Eng. 2006;34(1):23-38.

38. Moore A, Marecos E, Bogdanov A, Weissleder R. Tumoral distribution of long-circulating dextran-coated iron oxide nanoparticles in a rodent model. Radiology. 2000;214(2):568-574.

39. Berry CC, Wells S, Charles S, Curtis ASG. Dextran and albumin derivatised iron oxide nanoparticles: influence on fibroblasts in vitro. Biomaterials. 2003;24(25):4551-4557.

40. Gamarra LF, Brito GES, Pontuschka WM, Amaro E, Parma AHC, Goya GF. Biocompatible superparamagnetic iron oxide nanoparticles used for contrast agents: a structural and magnetic study. J Magn Magn Mater. 2005;289:439-441.

41. Tassa C, Shaw SY, Weissleder R. Dextran-coated iron oxide nanoparticles: a versatile platform for targeted molecular imaging, molecular diagnostics, and therapy. Accounts Chem Res. 2011;44(10):842-852.

42. Martin VM, Siewert C, Scharl A, et al. Immunomagnetic enrichment of disseminated epithelial tumor cells from peripheral blood by MACS Exp Hematol. 1998;26(3):252-264.

43. Islam T, Harisinghani MG. Overview of nanoparticle use in cancer imaging. Cancer Biomark. 2009;5(2):61-67.

44. Jain TK, Morales MA, Sahoo SK, Leslie-Pelecky DL, Labhasetwar V. Iron oxide nanoparticles for sustained delivery of anticancer agents Mol Pharm. 2005;2(3):194-205.

45. Wagner K, Kautz A, Roeder M, et al. Synthesis of oligonucleotidefunctionalized magnetic nanoparticles and study on their in vitro cell uptake. Applied Organometallic Chemistry. 2004;18(10): 514-519.

46. Moore A, Weissleder R, Bogdanov A Jr. Uptake of dextran-coated monocrystalline iron oxides in tumor cells and macrophages. J Magn Reson Imaging. 1997;7(6):1140-1145.

47. Reimer P, Schuierer G, Balzer T, Peters PE. Application of a superparamagnetic iron oxide (Resovist) for MR imaging of human cerebral blood volume. Magn Reson Med. 1995;34(5):694-697.

48. Kopp AF, Laniado M, Dammann F, et al. MR imaging of the liver with Resovist: safety, efficacy, and pharmacodynamic properties. Radiology. 1997;204(3):749-756

49. Reimer P, Balzer T. Ferucarbotran (Resovist): a new clinically approved RES-specific contrast agent for contrast-enhanced MRI of the liver: properties, clinical development, and applications. Eur Radiol. 2003;13(6):1266-1276.

50. Matuszewski L, Persigehl T, Wall A, et al. Cell tagging with clinically approved iron oxides: feasibility and effect of lipofection, particle size, and surface coating on labeling efficiency. Radiology. 2005;235(1): $155-161$.

51. Raynal I, Prigent P, Peyramaure S, Najid A, Rebuzzi C, Corot C. Macrophage endocytosis of superparamagnetic iron oxide nanoparticles: mechanisms and comparison of ferumoxides and ferumoxtran-10. Invest Radiol. 2004;39(1):56-63.

52. Zolnik BS, Gonzalez-Fernandez A, Sadrieh N, Dobrovolskaia MA. Nanoparticles and the immune system. Endocrinology. 2010;151(2):458-465. 
53. Yeh CH, Hsiao JK, Wang JL, Sheu F. Immunological impact of magnetic nanoparticles (Ferucarbotran) on murine peritoneal macrophages. J Nanopart Res. 2010;12(1):151-160.

54. Raynal I, Prigent P, Peyramaure S, Najid A, Rebuzzi C, Corot C. Macrophage endocytosis of superparamagnetic iron oxide nanoparticles Mechanisms and comparison of Ferumoxides and Ferumoxtran-10. Investigative Radiology. 2004;39(1):56-63.

55. Muller K, Skepper JN, Posfai M, et al. Effect of ultrasmall superparamagnetic iron oxide nanoparticles (Ferumoxtran-10) on human monocyie-macrophages in vitro. Biomaterials. 2007;28(9): 1629-1642.

56. Maurer-Jones MA, Bantz KC, Love SA, Marquis BJ, Haynes CL. Toxicity of therapeutic nanoparticles. Nanomedicine (London). 2009; 4(2):219-241.

57. Thomas R, Park IK, Jeong YY. Magnetic iron oxide nanoparticles for multimodal imaging and therapy of cancer. Int J Mol Sci. 2013;14(8): $15910-15930$
58. Mazaheri Y, Shukla-Dave A, Muellner A, Hricak H. MRI of the prostate: clinical relevance and emerging applications. J Magn Reson Imaging. 2011;33(2):258-274.

59. Jain R, Dandekar P, Patravale V. Diagnostic nanocarriers for sentinel lymph node imaging. J Control Release. 2009;138(2):90-102.

60. Harisinghani MG, Barentsz J, Hahn PF, et al. Noninvasive detection of clinically occult lymph-node metastases in prostate cancer. $N$ Engl J Med. 2003;348(25):2491-2499.

61. Jain KK. Advances in the field of nanooncology. BMC Med. 2010;8:83.

62. Banobre-Lopez M, Teijeiro A, Rivas J. Magnetic nanoparticle-based hyperthermia for cancer treatment. Rep Pract Oncol Radiother. 2013; 18(6):397-400.

63. Bhirde A, Xie J, Swierczewska M, Chen XY. Nanoparticles for cell labeling. Nanoscale. 2011;3(1):142-153.
International Journal of Nanomedicine

\section{Publish your work in this journal}

The International Journal of Nanomedicine is an international, peerreviewed journal focusing on the application of nanotechnology in diagnostics, therapeutics, and drug delivery systems throughout the biomedical field. This journal is indexed on PubMed Central, MedLine, CAS, SciSearch $\AA$, Current Contents ${ }^{\circledR} /$ Clinical Medicine,

\section{Dovepress}

Journal Citation Reports/Science Edition, EMBase, Scopus and the Elsevier Bibliographic databases. The manuscript management system is completely online and includes a very quick and fair peer-review system, which is all easy to use. Visit http://www.dovepress.com/ testimonials.php to read real quotes from published authors. 